\title{
Three-dimensional Finite Element Simulation Analysis of Urban Footbridge
}

\author{
Hengxiang Zheng ${ }^{a}$, Guiqiang Yang ${ }^{b}$ and Kelun Wei ${ }^{\mathrm{c}}$ \\ North China University Of Water Resources and Electric Power, Zhengzhou, Henan Province \\ 450011, P.R. China \\ a1106188360@qq.com, b794060423@qq.com, 'c1012921710@qq.com
}

Keywords: Urban footbridge; Finite element method; Static analysis

\begin{abstract}
In recent decades, a lot of quality and design problems of urban footbridge appear, these bridge problems often causes traffic jams and different traffic accidents, more serious bridge problem will cause certain people casualties. This paper uses universal finite element software ANSYS to establish three-dimensional finite element model of urban footbridge, and analyse and explain calculation results, and researchs stress and deformation distribution of urban footbridge under different cases. Research results can provide a certain reference basis for design and construction of the reinforced concrete urban footbridge.
\end{abstract}

\section{Introduction}

With the rapid development of urbanization process steps, population concentration, economic development, different vehicles is increasing, road congestion has become true, so urban footbridge became necessary traffic measures ${ }^{[1]}$. This urban footbridg is three spans beam structure in the longitudinal direction, bridge body is reinforced concrete structures, length of each span is $10 \mathrm{~m}$. Width of unilateral sidewalk is $0.5 \mathrm{~m}$, width of bridge deck is $2.2 \mathrm{~m}$. Width of girder is $25 \mathrm{~cm}$, height is $70 \mathrm{~cm}$. Width of secondary beam is $30 \mathrm{~cm}$, height is $40 \mathrm{~cm}$.

\section{Calculation Model}

Model Parameters. Concrete strength grade of bridge body is C30, density is $2500 \mathrm{~kg} / \mathrm{m}^{3}$, elastic modulus of concrete is $30 \mathrm{GPa}$, poisson's ratio of concrete is $0.167^{[2-3]}$. Density of reinforcement is $7800 \mathrm{~kg} / \mathrm{m}^{3}$, elastic modulus of concrete is $200 \mathrm{GPa}$, poisson's ratio of concrete is 0.3 .

Model Element. Bridge structure are simulated by using eight node isoparametric brick element, the element with 8 nodes is used in the $3 \mathrm{~d}$ model of the entity structure, have the characteristics of plasticity, creep, expansion, stress stiffening, large deformation, large strain, etc ${ }^{[4]}$. The element has 8 nodes, each node has three translational degrees of freedom. Finite element calculation model of urban footbridge structure shows in the figure 1.

Calculation Cases. Based on mechanical characteristics of urban footbridge structure during construction and operation period, mainly consider the following 3 kinds of calculation cases: case 1, dead weight and side span crowd load; case 2, dead weight and side span crowd load and middle span crowd load; case 3, dead weight and side span crowd load and middle span crowd load and seismic action. 


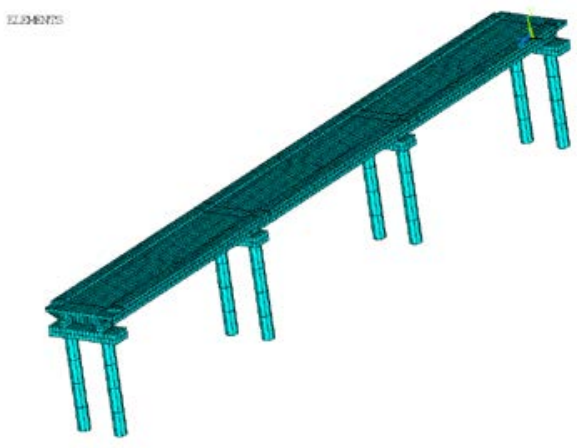

Fig.1 Finite element calculation model of urban footbridge structure

\section{Analysis of Calculation Results}

Stress Analysis. Through three-dimensional finite element simulation analysis of urban footbridge structure, can get stress nephogram of urban footbridge structure during construction and operation period, that shows in the figure 2 and figure 7.

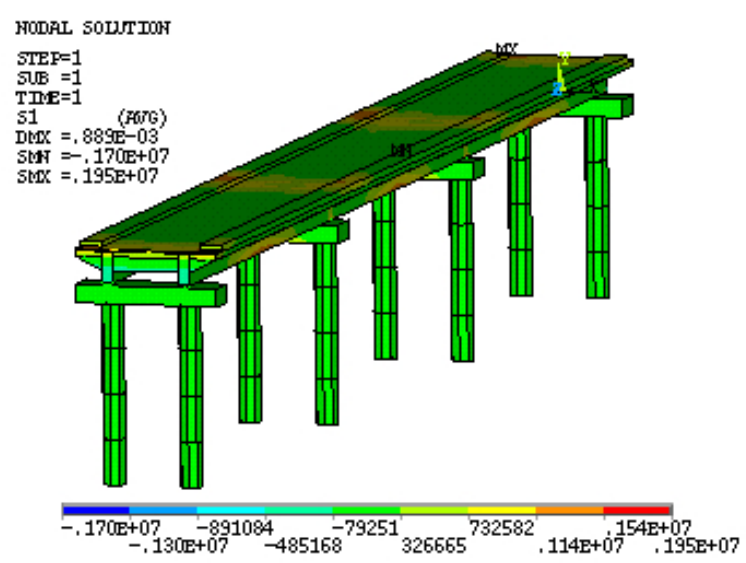

Fig.2 The first principal stress nephogram of urban footbridge under case $1(\mathrm{~Pa})$

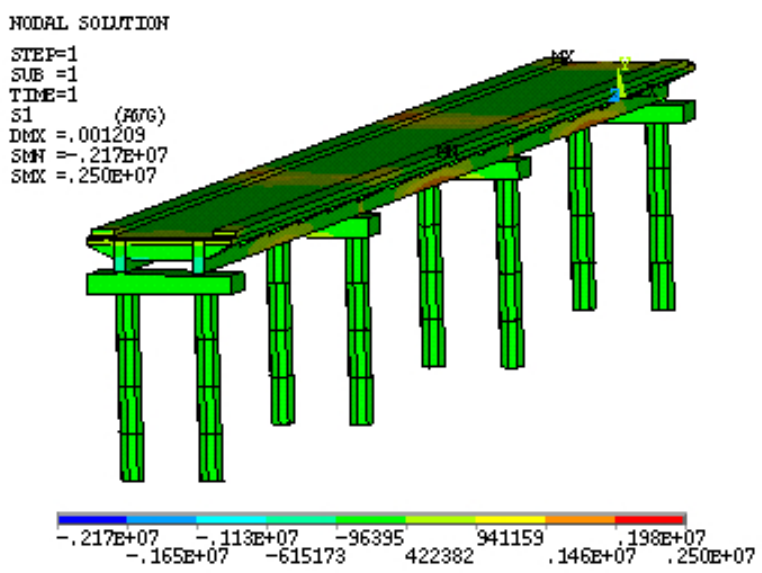

Fig.4 The first principal stress nephogram of urban footbridge under case $2(\mathrm{~Pa})$

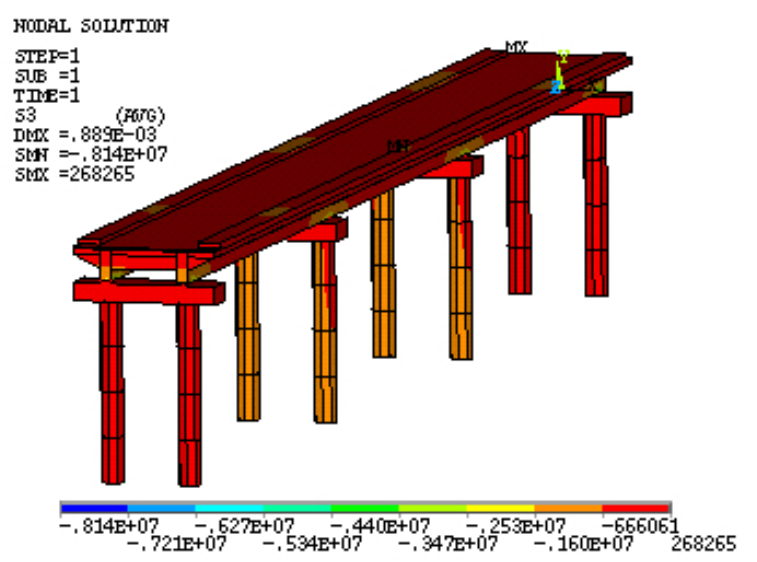

Fig.3 The third principal stress nephogram of urban footbridge under case $1(\mathrm{~Pa})$

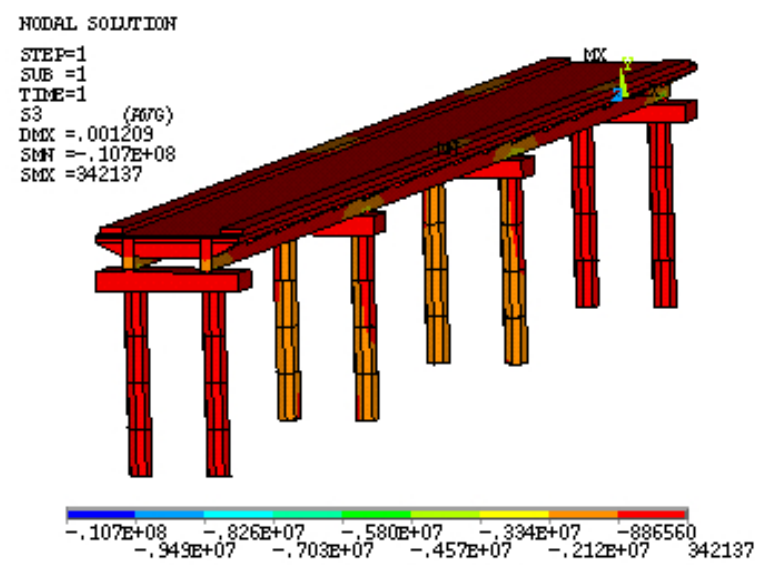

Fig.5 The third principal stress nephogram of urban footbridge under case $2(\mathrm{~Pa})$ 


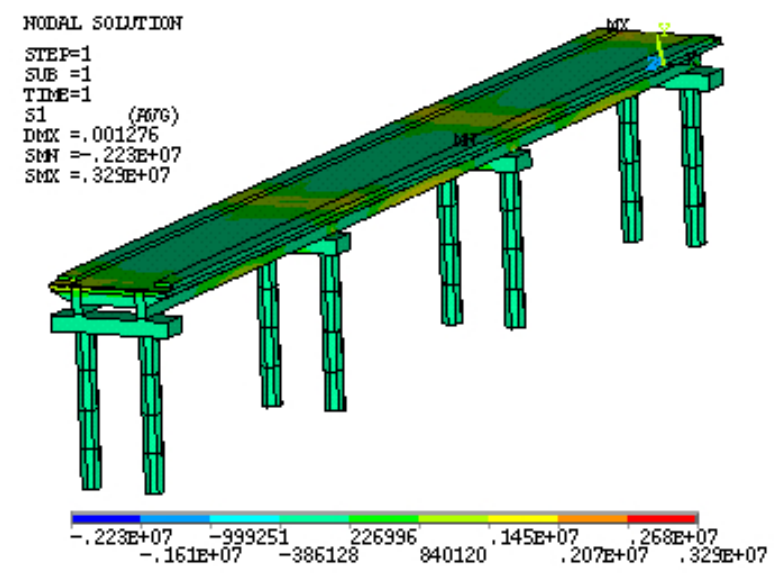

Fig.6 The first principal stress nephogram of urban footbridge under case $3(\mathrm{~Pa})$

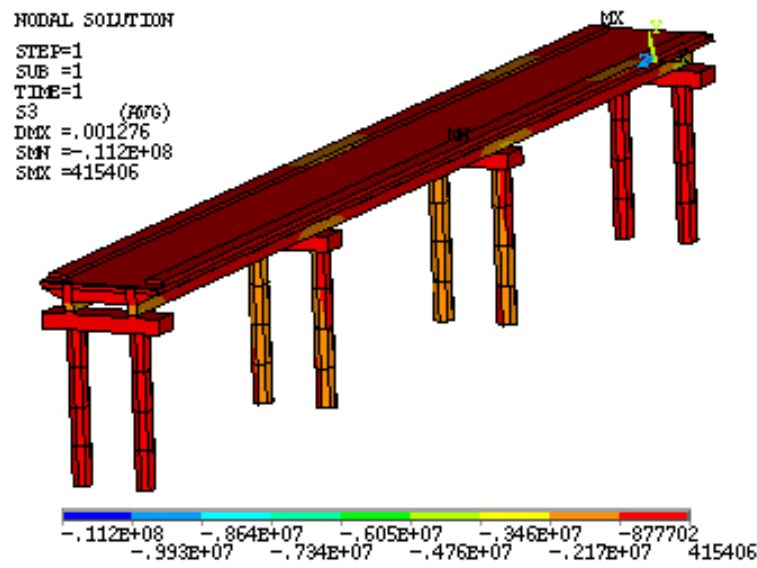

Fig.7 The third principal stress nephogram of urban footbridge under case $3(\mathrm{~Pa})$

As can be seen from the figure 2 to the figure 7, under different cases, the first principal stress of urban footbridge structure gradually increased with the increase of bridge load, maximum stress value of urban footbridge structure mainly appears in the junction of bridge pier and bridge deck, seismic action has large impact on stress. The maximum first principal stress is $3.29 \mathrm{MPa}$, which appears in the junction of bridge pier and bridge deck under case 3. The maximum third principal stress is -11.2 MPa, which appears in the junction of bridge pier and bridge deck under case 3 .

Deformation Analysis. Based on deformation analysis of urban footbridge structure, can get displacement change rule of urban footbridge structure under different cases, displacement nephogram of urban footbridge structure under different cases shows in the figure 8 and figure 13 .

As can be seen from the figure 8 to the figure 13, displacement value of urban footbridge structure under different cases is small, seismic action has large impact on total displacement value of urban footbridge structure, seismic action mainly produces horizontal displacement, which lead total displacement values to increase sharply. Under case 1, the maximum vertical displacement of urban footbridge structure is $0.89 \mathrm{~mm}$, the maximum total displacement of urban footbridge structure is $0.89 \mathrm{~mm}$; under case 2, the maximum vertical displacement of urban footbridge structure is $1.2 \mathrm{~mm}$, the maximum total displacement of urban footbridge structure is $1.2 \mathrm{~mm}$; under case 3, the maximum vertical displacement of urban footbridge structure is $1.2 \mathrm{~mm}$, the maximum total displacement of urban footbridge structure is $1.3 \mathrm{~mm}$.

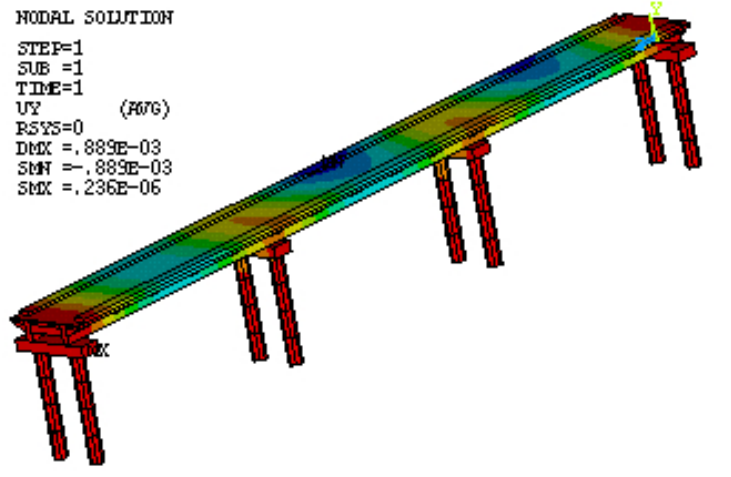

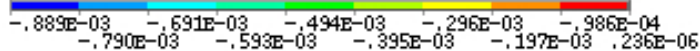

Fig.8 Vertical displacement nephogram of urban footbridge under case $1(\mathrm{~m})$

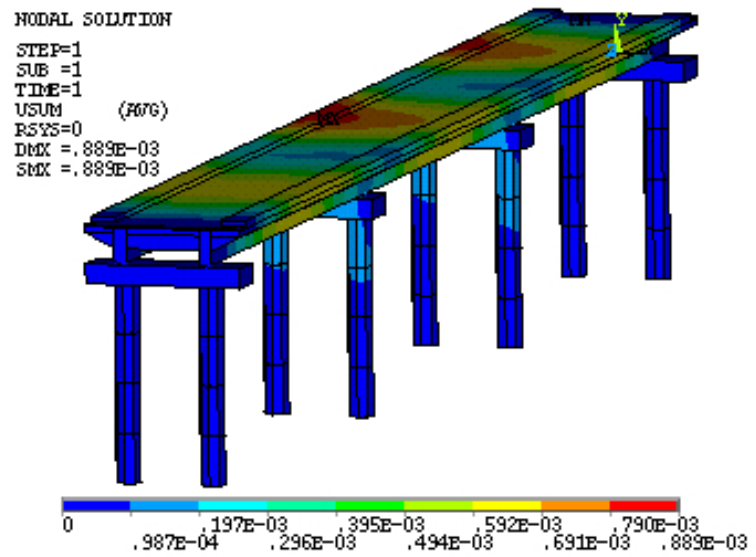

Fig.9 Total displacement nephogram of urban footbridge under case $3(\mathrm{~m})$ 


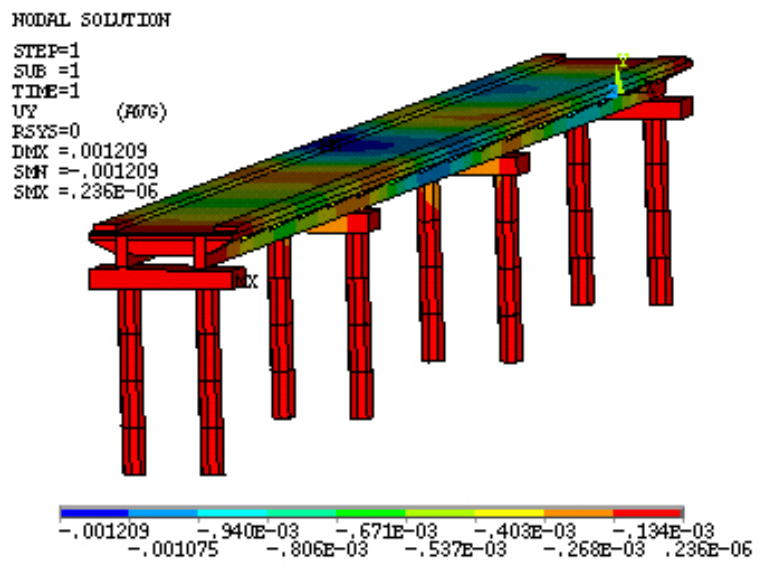

Fig.10 Vertical displacement nephogram of urban footbridge under case 2 (m)

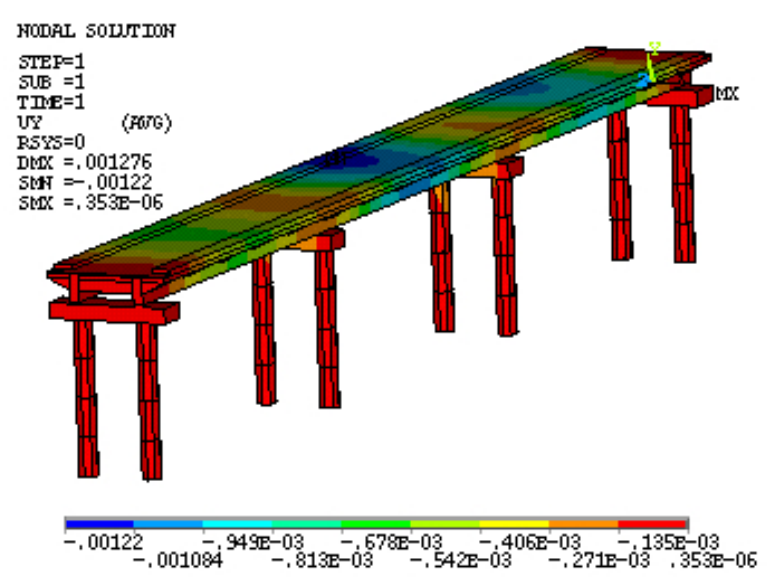

Fig.12 Vertical displacement nephogram of urban footbridge under case $3(\mathrm{~m})$

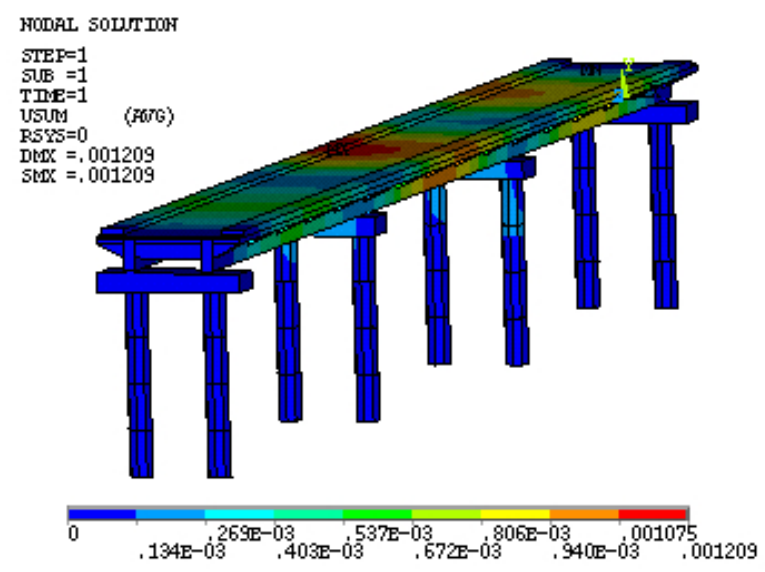

Fig.11 Total displacement nephogram of urban footbridge under case $2(\mathrm{~m})$

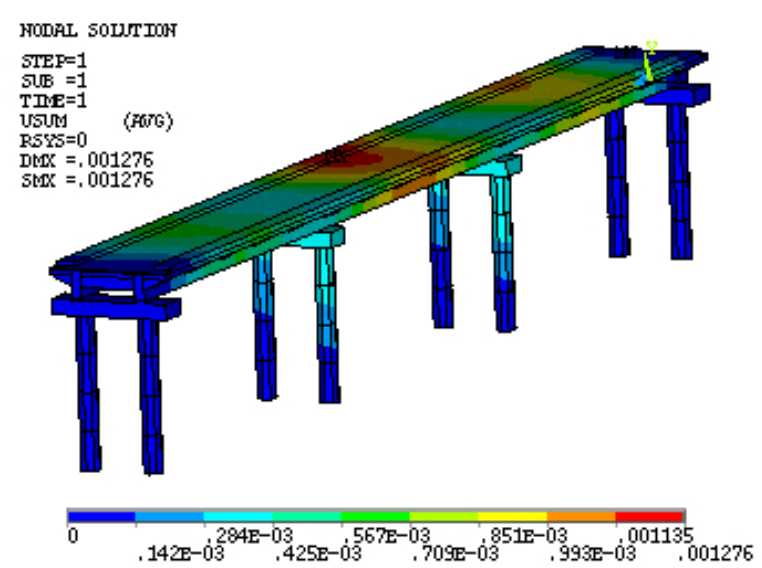

Fig.13 Total displacement nephogram of urban footbridge under case $3(\mathrm{~m})$

\section{Conclusion}

In conclusion, urban footbridge structure adopts reinforced concrete structure scheme is reasonable. The first principal stress of urban footbridge structure is small, can satisfy the strength requirement, structure is safe and reliable.

\section{Reference}

[1] Zhenhua Wang. The research and practice of highway old bridge strengthening technology [J]. Inner Mongolia Science Technology and Economy, 2008(14): 185-186.

[2] M.R. Shen, J.F. Chen: Rock Mechanics(Tsinghua University Press, China 2005)(in Chinese)

[3] X.CH. Wang: Finite Element Method (Tsinghua University Press, China 2003)(in Chinese)

[4] BoFang Zhu: Finite Element Method Principle and Application(China Water Conservancy and Hydropower Press, China 1998)(in Chinese). 